\title{
As fichas de cultura do Sistema de Alfabetização Paulo Freire: um "Ovo de Colombo"
}

\author{
Osmar Fávero \\ Universidade Federal Fluminense
}

\section{Resumo}

0 artigo retoma, inicialmente, as elaborações teóricas sobre cultura e cultura popular que fundamentaram a criação dos centros e movimentos de cultura e educação popular no Brasil nos anos de 1960. Apresenta, a seguir, o conceito antropológico de cultura assumido por Paulo Freire no Sistema de Alfabetização de Adultos, cuja primeira experiência foi realizada em Angicos, no Estado do Rio Grande do Norte, em 1963. Analisa o caráter inovador das fichas de cultura, motivadoras do processo de alfabetização. Reproduz e comenta as imagens artísticas dessas fichas, imagens feitas por Francisco Brennand para o Programa Nacional de Alfabetização, que seria implantado em todo o país, mas que foi bruscamente interrompido pelo golpe militar de 31 de março de 1964.

Palavras-chave: Cultura. Cultura popular. Alfabetização. Paulo Freire. Fichas de cultura. 


\section{Culture slides in Paulo Freire's Literacy System: an “Egg of Columbus"}

The article begins by revisiting the theoretical elaborations on culture and popular culture which served as the foundation for the creation of the centres and movements of popular culture and education the 1960's. It then presents the anthropological concept of culture adopted by Paulo Freire in the System of Adult Literacy whose first experience was carried out in Angicos (State of Rio Grande do Norte) in 1963. It analyses the innovative character of the culture slides, motivators of the literacy process. It reproduces and comments the artistic illustrations on these slides, designed by Francisco Brennand for the National Literacy Programme, which was to be implanted throughout the country, but it was abruptly interrupted by the military coup of 31st March 1964.

Keywords: Culture. Popular culture. Literacy. Paulo Freire. Culture slides.

\section{Las fichas de cultura del Sistema de Alfabetización Paulo Freire: un "Huevo de Colón”}

El artículo reanuda, inicialmente, las elaboraciones teóricas a respecto de la cultura y de la cultura popular que fundamentaron la creación de los centros y movimientos de cultura y educación popular, durante los años 1960. Presenta, a seguir, el concepto antropológico de cultura, asumido por Paulo Freire en el Sistema de Alfabetización de Adultos, cuya primera experiencia fue realizada en Angicos/RN, en 1963. Analiza el carácter innovador de las fichas de cultura, las cuales son motivadoras del proceso de alfabetización. Reproduce y comenta las imágenes artísticas de esas fichas, hechas por Francisco Brennand para el Programa Nacional de Alfabetización, que sería implantado en todo el país, pero que fue bruscamente interrumpido por el golpe militar del 31 de marzo de 1964.

Palabras clave: Cultura. Cultura Popular. Alfabetización. Paulo Freire. Fichas de cultura. 


\section{Os tempos áureos da cultura popular e da educação popular}

Conta-se que, em uma ocasião, Cristóvão Colombo foi convidado para um banquete no qual the haviam designado um posto de honra. Um dos convidados era um cortesão muito enciumado do grande descobridor. Quando teve a oportunidade, dirigiu-se a ele e the perguntou de uma forma um tanto impertinente: - Se você não tivesse descoberto a América, por acaso não existiriam outros homens na Espanha que poderiam fazê-lo? Colombo preferiu não responder diretamente. Levantou-se, pegou um ovo de galinha e convidou todos os presentes para tentar colocá-lo de forma que se mantivesse em pé sobre um de seus extremos. Quase todos os presentes tentaram, um após o outro, ante o olhar atento dos demais, uns com mais, outros com menos convicção. Mas passava o tempo e ninguém conseguia descobrir uma maneira do ovo ficar em equilíbrio. Finalmente Colombo pôs-se em pé, com ar solene, aproximou-se, pegou o ovo e bateu-o levemente contra a superfície da mesa, até que quebrou um pouco da casca de uma das pontas e, graças a este pequeno achatamento, o ovo se manteve na posição vertical. - Claro que desta maneira qualquer um pode fazê-lo! - objetou, um pouco alterado, o cortesão. Respondeu Colombo: - Sim, qualquer um, mas qualquer um a que se the tivesse ocorrido fazê-lo.

Fonte: www.metaforas.com

No início dos anos de 1960, quando foram criados os movimentos e centros de cultura popular no país, aos quais se subordinava a educação popular, todos partiam praticamente do mesmo conceito de cultura. Com expressões mais ou menos elaboradas, todos entendiam a cultura como a transformação dialética do mundo natural, previamente dado, em um mundo humano, historicamente construído.

As primeiras formulações foram feitas, do lado do grupo marxista, por Carlos Estevam, um dos criadores e o primeiro Presidente do Centro Popular de Cultura (CPC) da União Nacional dos Estudantes (UNE), no livro A questão da cultura popular, de 1963. Do lado do grupo católico, elas tiveram origem nos seminários realizados, no período, pelo padre jesuita Henrique de Lima Vaz, para os militantes da Juventude Universitária Católica (JUC) e assumidos pela Ação Popular (AP), criada em 1962, após a crise da JUC com a hierarquia eclesiástica. Vejamos o essencial dessas duas formulações.

A perspectiva de luta pela libertação nacional, à qual a cultura popular se liga intimamente, é posta em termos concretos por Carlos Estevam (1963). Por sua formação marxista, é o que melhor explicita a relação entre cultura e revolução. Para ele: "A cultura popular é uma forma legítima de trabalho revolucionário na medida em que tem por objetivo acelerar a velocidade com que se transformam os suportes materiais da sociedade" (Estevam, 1963, p. 4). Citando Guevara - o qual, perguntado como se fazia uma reforma agrária, respondeu: “É muito simples. Primeiro, toma-se o poder. Depois, faz-se a reforma agrária."-, Estevam afirma: "Por mais que se faça, no essencial, a cultura permanece intacta enquanto não se 
toma o poder" (1963, p. 5). E esclarece: "Cultura popular não é mais que uma forma mediadora entre cultura e revolução" (Estevam, 1963, p. 6). Acrescenta que "não é mais que uma reforma, mas uma reforma no sentido revolucionário porque sabe unir dialeticamente a possibilidade imediata ao objetivo final e porque assume como objetivo final a transformação material da sociedade" (Estevam, 1963, p. 7).

É importante apresentar o que Estevam entende por cultura popular, principalmente porque representa uma das fontes de elaboração e divulgação desse conceito, por meio do CPC da UNE, incorporado, em parte ou totalmente, por várias organizações locais'.

Para definir cultura popular, Estevam parte de um conceito amplo de cultura: "tudo o que não é exclusivamente natureza", o que para ele compreende, no mundo moderno, uma infinita variedade de bens, utensílios e instrumentos, de atividades de produção, reprodução, manutenção e administração, de normas, preceitos e símbolos, de ideias, crenças e sentimentos, de costumes, técnicas e organizações que constituem, enfim, todo um complexo universo criado pelo trabalho e que tem por finalidade garantir, em um nível cada vez mais integral, a realização do ser do homem no mundo (Estevam, 1963, p. 8).

Dessa visão de cultura, por ser demais ampla, Estevam distingue, no entanto, os elementos materiais dos espirituais e estabelece uma primeira restrição: “A cultura entendida assim nessa acepção mais corrente se resume às atividades e aos produtos que têm seu destino na consciência", ou seja, as ciências, as artes, o direito, a religião, a filosofia, as atitudes, os símbolos, as crenças, os projetos, a linguagem e os valores (Estevam, 1963, p. 9). O conteúdo do termo "popular", aposto a este conceito restrito de cultura, estabelece uma segunda restrição:

A cultura popular, essencialmente, diz respeito a uma forma particularíssima de consciência, a consciência que imediatamente deságua na ação política. Ainda assim, não a ação política em geral, mas a ação política do povo. Ela é o conjunto teórico-prático que codetermina, juntamente com a totalidade das condições materiais objetivas, o movimento ascensional das massas em direção à conquista do poder na sociedade de classes. (Estevam, 1963 p. 29-30).

Para Estevam, essa finalidade constituía a própria razão de existir da cultura popular: “[...] ela só existe se se comporta como uma força de caráter cultural que age com o objetivo de tornar consciente para as massas o sentido de sua situação histórica" (1963, p. 30). Dessa forma, pode-se dizer que são atividades de cultura popular todas aquelas "relativas à formação da consciência política ativa das mas-

1. Posteriormente, Ferreira Gullar (1963), terceiro e último Presidente do CPC da UNE, em Cultura posta em questão, apresenta uma concepção de cultura popular distinta e bastante mais aberta que a de Carlos Estevam. No entanto, a concepção do primeiro foi a mais difundida, no período em estudo. 
sas" (Estevan, 1963, 30).

Por sua vez, ao lado dos temas consciência e ideologia, o tema cultura é fundamental na reflexão de Pe. Vaz. ${ }^{2}$ Ele a considera a forma concreta da consciência histórica numa determinada época, não somente enquanto criação dos homens nesse tempo, mas também enquanto compreendida e vivida por esses mesmos homens. Pela consciência histórica, o homem reconhece o mundo humano; pela cultura o constrói, afirmando-se nele como homem. Do ponto de vista filosóficoantropológico, a natureza exprime o que é dado ao homem; a cultura, o que é por ele feito. 0 mundo de cultura é, assim, o mundo propriamente humano.

Considera Pe. Vaz que a consciência contém dois planos que se interceptam: a) o plano da intenção, que, voltada para alguma coisa, quando tem sempre algo a enfrentar, está sempre em luta; e b) o plano da expressão, que se constitui na recriação, é a forma nova que o homem dá ao objeto do qual ele tem consciência para comunicar aos outros homens. Em correspondência, a cultura tem dois aspectos: al o subjetivo, que exprime a cultura como desenvolvimento do sujeito que edifica o mundo cultural, seja o indivíduo, sejam grupos sociais mais amplos, seja a humanidade, que tende a constituir um sujeito cultural universal; b) o objetivo, que exprime a cultura como processo de desenvolvimento do mundo a ser transformado pelo homem, ou seja, as obras culturais, que são formas de cultura. Do mesmo modo que a consciência é sempre intenção-expressão, também a cultura conjuga dialeticamente dois momentos análogos, em um processo que é o próprio processo histórico: realização do homem e do mundo humano; personalização e socialização. 0 aspecto subjetivo, por sua vez, desdobrar-se-ia em duas dimensões, cuja origem é a mesma e única, ou seja, o ato de transformação dialética do mundo: a dimensão de consciência que engloba ideias, valores, projetos; e a dimensão do agir, que compreende os instrumentos e as técnicas de transformação do mundo.

Com base nesses elementos, Pe. Vaz propõe uma definição de cultura que passa a ser reproduzida e utilizada largamente pela Ação Popular, da qual se desdobram suas propriedades:

Cultura é o processo histórico (e, portanto, de natureza dialética) pelo qual o homem, em relação ativa (conhecimento e ação) com o mundo e com os outros homens, transforma a natureza e se transforma a si mesmo, constituindo um mundo qualitativamente novo de significações, valores e obras humanas, e realizando-se como homem neste mundo humano. (Fávero, 1983, p. 16-18).

2. As colocações de Pe. Vaz foram feitas, inicialmente, no Curso sobre Consciência Histórica e Cristianismo, durante o $3^{\circ}$ Seminário Nacional de Estudos da JUC (Aracaju, fev. 1963), e foram assumidas pela Ação Popular (AP) no mesmo ano de 1963, no documento normativo Cultura Popular, utilizado como fonte para este texto (Cf. Fávero, 1983, p. 15-31). São também encontradas nos textos propostos pelo Movimento de Educação de Base (MEB) como Fundamentação dos livros de leitura Saber para Viver e Viver e Lutar, em 1964, e do Programa Didático para 1965 (1ª parte - Estudos sociais: cultura). 
Em decorrência dessa definição, são fixadas as propriedades da cultura:

a) A cultura é histórica, pois a iniciativa humana que cria a história é precisamente a cultura. A história não é mais que o desenvolvimento do processo pelo qual se opera a passagem dialética da natureza em cultura, ou seja, do mundo natural em mundo humano.

b) A cultura é social, pois só tem sentido e validez enquanto processo de comunicação das consciências. 0 mundo cultural, como mundo humanizado, sendo mundo-para-mim é mundo-para-o-outro.

c) A cultura é pessoal, pois é por excelência iniciativa de liberdade, enquanto supera o determinismo da natureza. Logo, a comunicação das consciências [...] só pode ser entendida na forma de livre apelo à realização da pessoa, ou seja, à aceitação ativa e livremente consentida das significações e ideias do mundo natural em que o indivíduo se inscreve. Só enquanto pessoal a cultura é mediadora de libertação, isto é, de aprofundamento da consciência-de-si, de passagem do homem "coisa e objeto" (natureza) para o homem "sujeito e pessoa" (história).

d) A cultura é universal. Pelo conteúdo humano de suas significações laspecto subjetivo) e pela destinação humana de suas obras (aspecto objetivo), o processo cultural tende a constituir-se em elemento de mediação entre todos os homens. Essa universalidade é concreta, pois historicamente encarnada. E é como intencionalmente universal que a cultura deve ser dita popular e também nacional: enquanto integra as consciências dentro da nação no plano de sua realização humana e as situa na linha do movimento histórico essencial de universalização efetiva e de criação de uma cultura para todos os homens.

A tarefa de criação cultural teria, então, ainda segundo Pe. Vaz, duas direções: transformação da natureza e comunicação com os outros homens. A primeira direção sintetiza o aspecto da cultura como luta; é tarefa concreta em relação à natureza e ao trabalho propriamente dito. A segunda identifica-se com esta afirmação: toda obra de cultura é uma palavra dirigida ao outro.

Em outro plano, coloca Pe. Vaz que a polarização ideológica, característica da cultura contemporânea, manifesta-se particularmente na oposição entre cultura popular e cultura de elite. Esta última, entendida como a cultura aristocrática ideologizada, embora se declare destinada a todos, serve aos interesses de uma classe, afirmando como universais valores que são apenas dessa classe. Por sua vez, a significação mais profunda da cultura popular não é a descoberta de valores culturais "autênticos" no meio do povo, nem a valorização do folclore; é precisamente entrar em tensão ideológica contra a cultura de uma classe. Só 
assim se explica o aparecimento de movimentos de cultura popular no mundo todo, com diferentes expressões, mas que apenas na esfera política encontram seu sentido último.

\section{Contrapondo as definições}

Dois pontos da exposição de Carlos Estevam (1963), muito fortes no anteprojeto do Manifesto do Centro Popular de Cultura ${ }^{3}$, merecem destaque, em contraponto com as posições de Pe. Vaz, assumidas pelo grupo cristão. Em primeiro lugar, a afirmação de que os artistas e intelectuais do CPC da UNE distinguiam-se "dos demais grupos e movimentos existentes no país" pela "clara compreensão de que toda e qualquer manifestação cultural só pode ser adequadamente compreendida quando colocada à luz de suas relações com a base material sobre a qual se erigem os processos culturais de superestrutura" (Estevam, 1963, p. 81). Mas a esta afirmação conjuga-se o reconhecimento da autonomia relativa do cultural, ou de que "cada setor da superestrutura pode reagir dialeticamente sobre a base econômica e manter em relação a esta base certa independência de movimentos" (Estevam, 1963, p. 82). A própria condição de existência do CPC é dada, pois, pela possibilidade de a consciência "adiantar-se em relação ao ser social e converterse, dentro de certa medida, em uma força modificadora do ser social" (Estevam, 1963, p. 82). Pode-se ver claramente, então, que o CPC da UNE não trabalha com o conceito de consciência-reflexa, várias vezes criticado por Pe. Vaz. Nem mesmo trabalha apenas com os conceitos de consciência-produto ou consciênciainstrumento, "concepções materialistas" que são rejeitadas pelo grupo cristão por anularem a especificidade da consciência e, em última análise, anularem no homem sua condição de pessoa.

Em segundo lugar, ainda segundo Estevam (1963, p. 88), os intelectuais e artistas do CPC da UNE assumem a posição explícita de vanguarda: "Os membros do CPC optaram por ser povo, destacamento do seu exército no front cultural". Essa é uma diferença essencial com o grupo cristão, como afirma Marilena Chauí (1983, p.85): "Os artistas do CPC não optaram por aquilo que outros, cristãos, costumam chamar de 'comunidade de destino', isto é, a partilha da existência em comum. [...] Optaram por ser a vanguarda do povo, condutores, dirigentes, educadores". E talvez se possa aplicar ao CPC da UNE a mesma conclusão que ela tira para os Cadernos do Povo: essa postura condiciona o estilo pedagógico do CPC: “[...] antes persuasão que discussão e esclarecimento" (Chauí, 1983, p.83).

3. 0 anteprojeto do Manifesto foi publicado em Estevam (1963, p.79-109) De acordo com o próprio Estevam (1963, p. 77), foi escrito em março de 1962 e discutido durante todo esse ano, quando da formação dos CPC estaduais, por ocasião da UNE-Volante. Marilena Chauí (1983) faz uma crítica bastante radical às posturas desse Manifesto e dos Cadernos do Povo Brasileiro. 


\section{A incorporação desses conceitos pelos movimentos de cultura e educação popular}

Ao final de 1963, está bastante claro para todas as organizações que a cultura popular não é apenas uma atitude visando à democratização da cultura, mas um movimento que quer a transformação da realidade para a libertação das classes dominadas. 0 conjunto de relatórios e comunicações apresentado pelos participantes no $1^{\circ}$ Encontro Nacional de Alfabetização e Cultura Popular, realizado no Recife, em setembro de 1963, sob o patrocínio do MEC e com apoio local do Movimento de Cultura Popular (MCP) 4 , permite verificar o nível de incorporação dos conceitos de cultura e cultura popular pelos movimentos estaduais e locais. Vários movimentos assumem a crítica à dominação cultural dos centros hegemônicos. Por exemplo, lê-se no relatório da Campanha “De Pé no Chão também se Aprende a Ler", de Natal:

O significado do termo Cultura Popular assume para nós forma definida a partir da compreensão mais profunda da situação de dominação externa a que está submetido o Brasil, desde o seu descobrimento, até os dias atuais. Dominação que tem sofrido, historicamente, mudanças que ora explicitam ou atenuam seu caráter, mas que fundamentalmente persiste, envolvendo todo o complexo político-econômico e cultural brasileiro. Começa então o povo brasileiro a assumir um tipo de cultura que não é elaborada aqui e que tem a função precípua de manter nosso povo preso a um esquema de pensamento e atitudes que devem traduzir-se na aceitação passiva da dominação externa e no respeito e admiração do povo dominador. Há, portanto, um entrelaçamento dialético entre cultura popular e libertação nacional, socialismo e luta anti-imperialista. Por conseguinte, embora pareça em princípio paradoxal, a cultura popular tem papel de instrumento de revolução econômico-social, mas, em última instância, a afirmação e a vitória desta revolução é que irá possibilitar o surgimento das mais autênticas criações populares, livres das alienações que se processam no plano político e econômico. Fica claro, portanto, o mais profundo sentido dialético da revolução popular, que não é um fim, mas um meio de conseguir a libertação total do povo, fazendo-o construtor do seu destino. Nenhum povo é dono do seu destino se antes não for dono de sua cultura. (Fávero, 1983, p. 71-75; Soares; Fávero, 2009, p. 135-139).

Também o CPC de Belo Horizonte (Fávero, 1983, p.84-85; Soares e Fávero, 2009, p. 170-171) apresenta formulação equivalente, marcando ainda mais o caráter seletivo da cultura e da educação, em função das classes sociais. Após recolocar os conceitos usuais do homem como criador da cultura, e a cultura como mediadora da comunicação entre os homens, exprime os condicionamentos da "cultura brasileira" (aspeada no texto) sob dois aspectos:

4. Ver SOARES, Leôncio e FÁVERO, Osmar (2009). 
1. A "cultura brasileira" como privilégio de uma classe culturalmente dominante. Os meios formais de educação estão voltados para a elite e seus interesses. 0 povo não tem acesso a esses meios.

2. A "cultura brasileira” é uma cultura de reflexão, na medida em que caracteriza uma imposição por parte dos grupos culturalmente dominantes. E o mais agravante é que esta cultura imposta é sempre uma cultura importada.

Afirma, em consequência, que o movimento de cultura popular surge no Brasil como reivindicação, opondo-se à cultura que serve apenas à classe dominante, devendo ser, ao mesmo tempo, um movimento que elabore com o povo le não para o povol uma cultura autêntica e livre. Para isso, deveria ter como objetivos: a curto prazo, conscientização e organização do povo; e, a longo prazo, a tomada do poder, enquanto processo de libertação e instrumento de transformação.

O Movimento de Educação de Base (MEB), por sua vez, assumiu integralmente essa perspectiva e, tal como fez com o conceito de educação de base, relacionou o significado da cultura popular à conscientização, tendo em vista a opção por um projeto histórico de transformação:

Como a integração de todos os homens na mesma cultura vincula-se a uma transformação dos padrões econômicos, políticos e sociais, a cultura popular está também vinculada à realização de um projeto histórico que pretende aquelas transformações. Um projeto histórico condizente com uma cultura elaborada e participada por todos. Um projeto que possibilite a todo o povo assumir o seu papel de criador e sujeito de cultura da sociedade em que vive. Sendo assim, pode-se dizer que cultura popular não é um fenômeno neutro, indiferente. Ao contrário, nasce de um conflito e nele desemboca, pois ela existe e se apresenta sempre em termos de libertação, de promoção humana, no sentido mais amplo. Donde se conclui que não é possível um trabalho de cultura popular desligado do processo de conscientização. E, por estar ligada a este processo, é que ela deve levar sempre a uma opção. Deve dar possibilidades de opção ao povo, embora não possa impor essa opção, porque ela deve ser encontrada pelo próprio povo. Esta opção decorre da plena consciência que o homem adquire das diferenças e desníveis entre os grupos que formam a sociedade e da necessidade de uma transformação dos padrões culturais, políticos, sociais e econômicos que os determinam. (MEB, 1965, p. 9).

O MCP é o que melhor expressou este tema, naquela oportunidade:

Um movimento de cultura popular só surge quando o balanço das relações de poder começa a ser favorável aos setores populares da comunidade e desfavorável aos seus setores de elite. Esta nova situação caracteriza, de modo genérico, o quadro atual da vida brasileira. [...]

0 movimento popular gera o movimento de cultura popular. 0 movimento popular, ao atingir determinada etapa de seu processo de desenvolvimento, experimenta a necessidade de liquidar certos entraves de ordem cultural que se apresentam 
como barreiras características daquela etapa, obstaculizando a passagem para a etapa seguinte. A superação de tais dificuldades se apresenta como condição para o prosseguimento do processo.

0 movimento popular não gera um movimento cultural qualquer. Gera, precisamente, um movimento de cultura popular. Os interesses culturais do movimento popular têm, portanto, um caráter específico: exprimem a necessidade de uma produção cultural, a um só tempo voltada para as massas e destinada a elevar o nível de consciência social das forças que integram, ou podem vir a integrar, o movimento popular.

A demanda por uma consciência popular adequada ao real e possuída pelo projeto de transformá-lo é característica do movimento popular porque este se assenta nas três seguintes pressuposições: al só o povo pode resolver os problemas populares; b) tais problemas se apresentam como uma totalidade de efeitos que só pode ser corrigida pela supressão de suas causas, radicadas nas estruturas sociais vigentes; $c$ ) o instrumento que efetua a transformação projetada é a luta política guiada por ideias que representam adequadamente a realidade objetiva. (Fávero, 1983, p. 90-91; Soares; Fávero, 2009, p. 60-621.

\section{0 conceito antropológico de cultura}

A proposta de educação de adultos de Paulo Freire foi elaborada no bojo deste "caldo ideológico". Além da produção de Pe. Vaz, assumida pela AP e pelo MEB como orientação para os militantes e agentes, a fundamentação teórica do Sistema Paulo Freire foi divulgada intensamente por todo o país, por ele próprio e sua equipe do Serviço de Extensão Cultural da então Universidade do Recife, no segundo semestre de 1963 e nos primeiros meses de 1964.

As matrizes teóricas dessas formulações são praticamente as mesmas e, de uma maneira ou de outra, os elementos fundamentais do conceito filosóficoantropológico de cultura delas derivadas foram assumidos pelos grupos, sobretudo de $A P$, que se encarregaram da implantação do Sistema de Alfabetização nos vários estados. Acredito que a elaboração foi simultânea, em Pe. Vaz e Paulo Freire, embora cada formulação guarde sua especificidade. É preciso ter presente que, sobretudo a partir de 1963, foi muito grande a interpenetração dos vários movimentos. Era comum a colaboração e a participação de estudantés e voluntários em várias frentes, simultaneamente, assim como a troca de experiências entre eles. Mais ainda, vivia-se um mesmo clima desenvolvimentista e contestatório e procurava-se, ao mesmo tempo, explicitar a ideologia por todos vivenciada. Era muito grande a circulação das mesmas ideias, certas ou erradas, nos vários grupos. As descobertas eram rapidamente conhecidas, divulgadas, criticadas, assimiladas, aplicadas. Os movimentos tinham reservas e preconceitos mútuos; mas os agentes, de uma maneira ou de outra, circulavam por todos eles.

No sistema de alfabetização proposto por Paulo Freire, cuja primeira experiência de repercussão nacional foi feita em Angicos, no Rio Grande do Norte, no primeiro 
semestre de 1963, o trabalho educativo com adultos, com base no diálogo, tem início com uma discussão sobre o conceito antropológico de cultura, motivado por uma série de dez fichas de cultura. 0 próprio Paulo Freire (1967, p. 108-109, grifo do autor) justifica esta opção:

E pareceu-nos que a primeira dimensão deste novo conteúdo com que ajudaríamos o analfabeto, antes mesmo de iniciar sua alfabetização, na superação de sua compreensão mágica como ingênua e no desenvolvimento de crescentemente crítica, seria o conceito antropológico de cultura. A distinção entre dois mundos: o da natureza e o da cultura. 0 papel ativo do homem em sua e com sua realidade. 0 sentido de mediação que tem a natureza para as relações e comunicação dos homens. A cultura como o acrescentamento que o homem faz ao mundo que não fez. A cultura como resultado de seu trabalho. Do seu esforço criador e recriador. 0 sentido transcendental de suas relações. A dimensão humanista da cultura. A cultura como aquisição sistemática da experiência humana. Como uma incorporação, por isto crítica e criadora, e não como uma justaposição de informes ou prescrições "doadas". A democratização da cultura dimensão da democratização fundamental. 0 aprendizado da escrita e da leitura como uma chave com que o analfabeto iniciaria a sua introdução no mundo da comunicação escrita. 0 homem, afinal, no e com o mundo. 0 seu papel de sujeito e não de mero e permanente objeto.

Este é certamente o aspecto mais genial do sistema de alfabetização de adultos criado no início dos anos de 1960. No entanto, não se encontra na obra de Paulo Freire, ou nos textos que fundamentam o sistema de alfabetização, a origem dela. Pela proximidade do próprio Paulo Freire, e também de participantes de sua equipe, com o grupo católico coordenado pela AP - e pelo fato de militantes da AP terem sido responsáveis pela implantação desse sistema em muitos estados -, pode-se supor que a elaboração de Pe. Vaz sobre o conceito de cultura e sua sistematização pela AP tenha sido determinante. Isto, no entanto, em nada diminui o mérito de Paulo Freire. Como teria dito Colombo: "Sim, qualquer um poderia fazê-lo, mas qualquer um a que se lhe tivesse ocorrido fazê-lo".

\section{As fichas de cultura}

Segundo Antonia Terra (2004, p. 156), os desenhos das fichas de cultura e das situações de aprendizagem que introduziam as palavras geradoras para a experiência de Angicos "foram feitos por um desenhista de Natal e os slides compostos pela equipe de Gastão Roberto Coaracy, do Rio de Janeiro". Esses desenhos eram bastante simples e o conjunto deles era, de certa forma, ainda incompleto, mas sabe-se terem sido enriquecidos durante as discussões nos círculos de cultura e revistos após a experiência. Recomendou-se, por exemplo, que, no caso das 
palavras geradoras, cada diapositivo apresentasse apenas uma imagem, à qual deveria associar-se apenas uma palavra.

Uma segunda série foi produzida pelo próprio MEC e editada pelo Instituto Nacional de Cinema Educativo (INCE), em 1963, para a experiência de Brasília. Os desenhos foram mais cuidados, adaptados à realidade local, e incorporaram a revisão feita após a experiência de Angicos ${ }^{5}$.

A série mais original é a terceira, com desenhos de Francisco Brennand, famoso pintor e ceramista do Recife, feita em meados de 1963 para o Programa Nacional de Alfabetização.

Lembro-me de que, neste período, no MEC, em Brasília, um grande grupo de coordenadores de centros e movimentos de cultura e educação popular aguardava uma reunião com o Ministro Paulo de Tarso. Paulo Freire mostrou aos mais próximos uma série de desenhos em aquarela, explicando: “Vejam o que ganhei do Brennand. Ele me disse: 'Você vai levar aqueles desenhos feios para o Ministro? Deixa que faço outros melhores.'" Recentemente, Brennand afirmou que produziu as referidas fichas pela intervenção de um amigo comum, Ariano Suassuna. Esta série original foi "requisitada" pelos militares, em um dos inquéritos a que foi submetido Paulo Freire, e nunca mais localizada.

Os desenhos eram reproduzidos em diapositivos, abrindo o "filminho" que seria usado nos círculos de cultura do Programa Nacional de Alfabetização, criado pelo MEC, no final de 1963. Coordenado por Paulo Freire, este programa pretendia alfabetizar 5 milhões de pessoas em dois anos. A experiência inicial, feita no antigo Estado do Rio de Janeiro, em áreas da Baixada Fluminense, a partir de janeiro de 1964, foi interrompida imediatamente após o golpe militar de 31 de março. Alguns poucos exemplares do "filminho" foram preservados. 0 que conseguimos obter ficou guardado durante 30 anos em uma geladeira, em Natal ${ }^{6}$.

É uma obra de arte e, como afirma Elisa Motta, recupera o modo tradicional de representação regional, na forma de xilogravura. Reproduzo, a seguir, a descrição dessas fichas de cultura, constante de sua monografia, apresentada para a conclusão do Curso de Pedagogia da Universidade Federal Fluminense ${ }^{7}$.

5. Sabe-se que existe outra série, preparada no início de 1964 pelo CPC de Goiânia, mas até hoje não se conseguiu acesso ao único original disponível.

6. Este "filminho", devidamente recuperado, mas com as marcas do tempo e de sua má conservação, está disponível em <www.forumeja.org.br/Educação Popular/Paulo Freire/PNA>. Os protótipos dos desenhos estão guardados no Museu Brennand, no Recife. O "filminho" usado na experiência de Brasília, por sua vez, foi encontrado há pouco tempo, após ficar mais de 40 anos guardado em um armário. Está no mesmo portal, juntamente com a série de Angicos e do PNA.

7. A monografia de Elisa Motta também está disponível em <www.forumeja.org.br/Educação Popular/Sistema Paulo Freire/Fichas de Cultura>. 
Como primeira observação sobre os desenhos de Brennand, percebo nas imagens características estéticas que remetem à arte popular. A simplicidade nos traços, a frontalidade, a escolha de motivos recorrentes na produção artística do povo: flores, frutas, rendas. Nenhum trabalho de alfabetização conhecido anteriormente teve tal preocupação estética. As imagens remetem à coloração do barro, apesar de, infelizmente, não se perceber, nos diapositivos, qual seja a cor original dos desenhos. São desenhos simples, com contornos bem marcados. Não há noção de profundidade nas imagens. (Motta, 2009, p. 65-75).

Nas fichas 1 e 2, o homem e a mulher estão com os pés descalços, representando a identidade rural, que valoriza a relação com a natureza e, sobretudo, com a terra. Na primeira situação, o homem está no centro, com uma enxada na mão e um livro na outra. É um homem do povo que lê, cria cultura por meio do trabalho, para suprir suas necessidades. Na segunda, persiste a visão antropocêntrica: 0 homem domina a natureza, domestica animais, sendo apresentado como elo de comunicação entre o mundo da cultura e o mundo da natureza.

Ficha 1: 0 homem diante da natureza e com a realidade

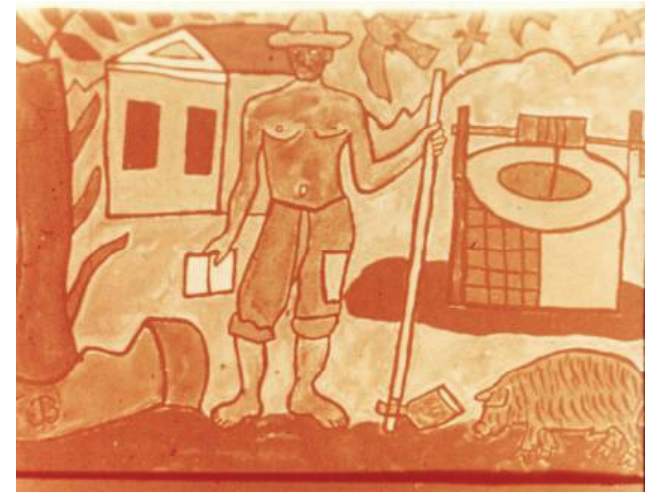

Ficha 2: A natureza - mediadora da comunicação entre o homem e o mundo da cultura

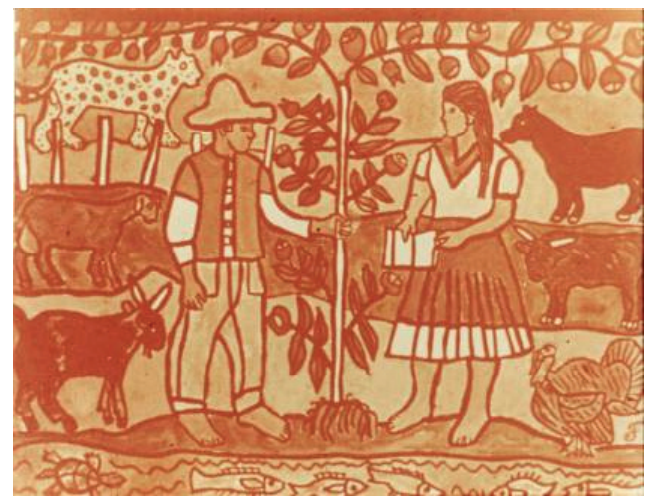


Ao apresentar, nas fichas 3, 4 e 5, a diferença ontológica entre os homens líndio e caçador) e o gato, que não realiza cultura ao caçar o rato, introduzindo a noção de cultura como produto de relações sociais, o Manual para os animadores, preparado em 1962 pela equipe de Paulo Freire no Serviço de Extensão Cultural da então Universidade do Recife, ainda insiste em uma ideia evolucionista de estágios, já bastante criticada na época pela produção antropológica. Afirma que o caçador está no "estágio de civilização", comparando-o com o índio. Estabelece, dessa forma, uma classificação hierárquica das diferenças, marcada pelo etnocentrismo.

No apêndice do livro Educação como prática da liberdade, elaborado após as experiências da década de $1960^{8}$, Paulo Freire apresenta a discussão ocorrida em círculos de cultura a partir das fichas e não nega a existência de cultura e de educação nas sociedades indígenas. Diz que o caçador e o índio estão em "fases histórico-culturais" distintas, ou seja, o homem iletrado vive oprimido; com a alfabetização o homem passa a pertencer a uma cultura letrada e poderá deixar de ser oprimido, tornando-se sujeito de sua história.

\section{Ficha 3: 0 caçador iletrado}

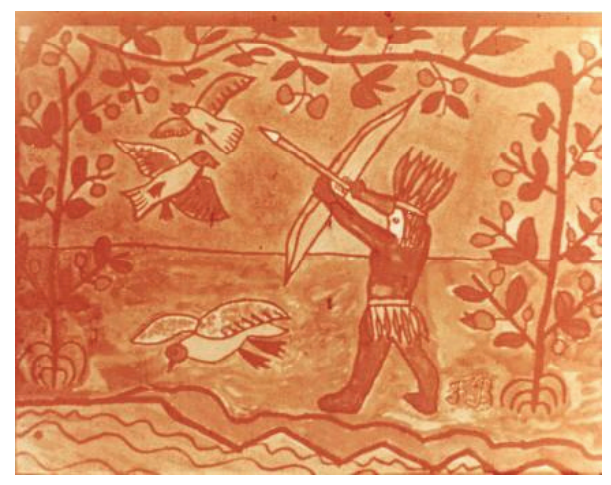

Ficha 4: 0 caçador civilizado

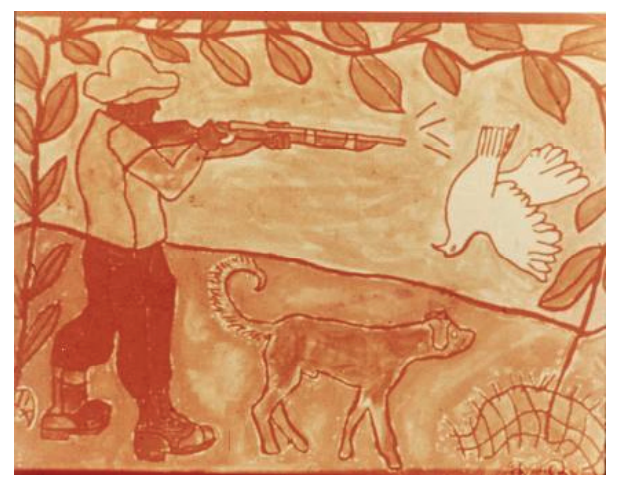

8. A primeira edição deste livro, feita pela Editora Paz e Terra, é de 1967. 
Ficha 5: 0 gato caçador

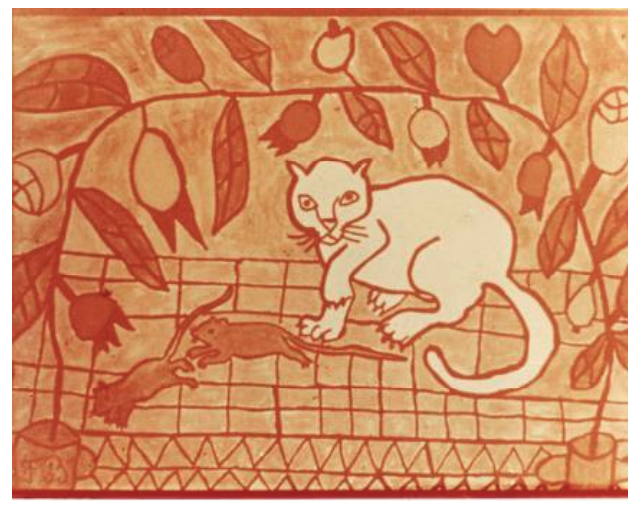

Nas fichas 6, 7 e 8, a criação popular, representada na primeira por dois homens em uma olaria, fabricando utensílios de barro, e na segunda por uma poesia de cordel e um arranjo de flores, a cultura é apresentada por meio de produtos culturais.

Ficha 6: Homens trabalhando o barro

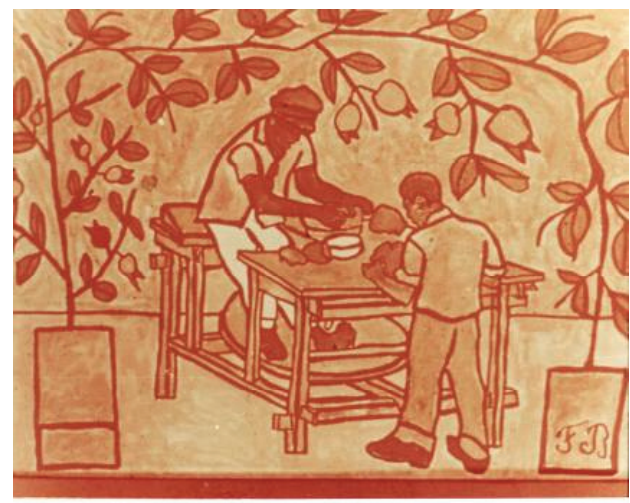

Ficha 7: 0 jarro de barro

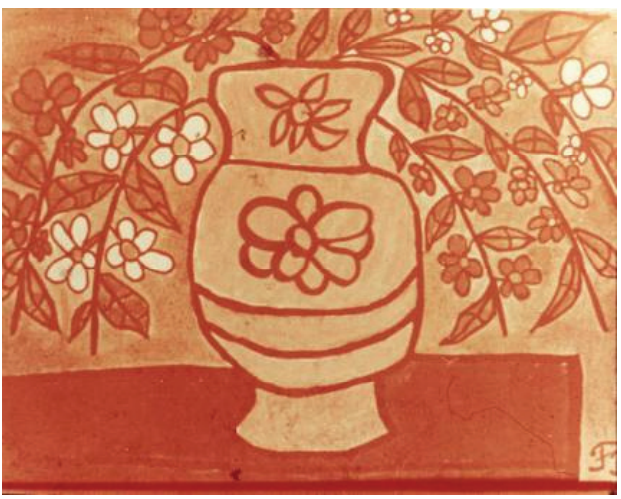


Ficha 8: 0 livro e a poesia

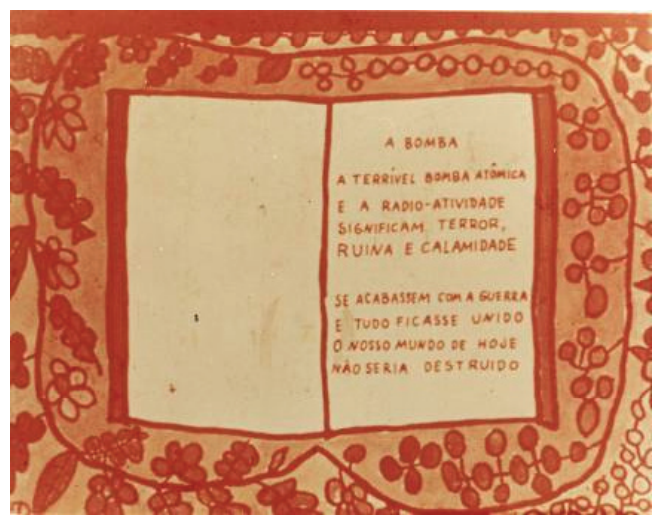

0 gaúcho e o vaqueiro da imagem 9 são apresentados como produtos de manifestações culturais distintas, definidas por padrões de comportamento, também diferentes, que não se prestam a generalizações. É um modo de abordar o fenômeno social, em que se pretende descobrir as atitudes funcionais mais do que as relações fundamentais de cada aspecto cultural particular. No entanto, sabe-se que a análise dessa situação nos círculos de cultura sempre foi muito rica, dando origem a discussões baseadas nos aspectos da caracterização dos padrões de comportamento como manifestação cultural.

\section{Ficha 9: 0 gaúcho e o vaqueiro}

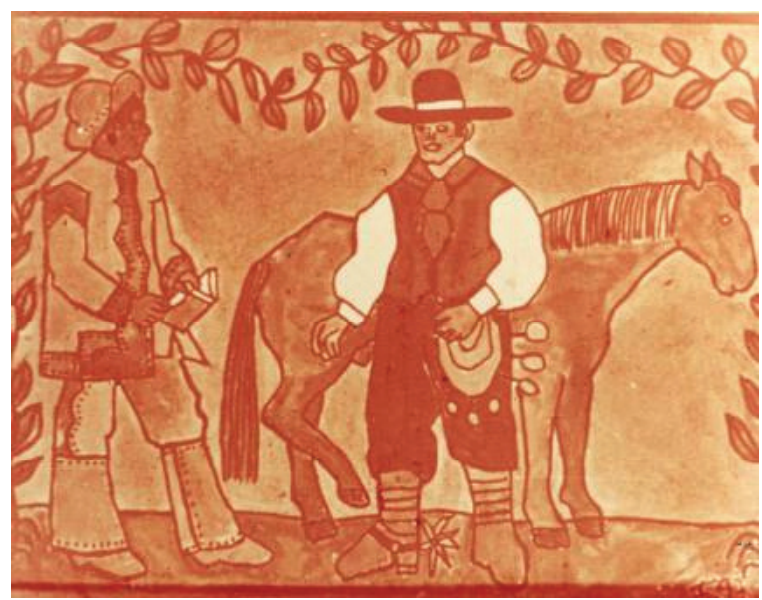

Suas representações remetem às descrições literárias de José de Alencar e Euclides da Cunha, reforçando os tipos humanos criados a partir da relação com o cenário da paisagem cultural, solenizadas na iconografia de Percy Lau ${ }^{9}$ e nos

9. Ilustrações feitas para a Revista Brasileira de Geografia, reproduzidas na obra Tipos e aspectos do Brasil. $7^{a}$ edição comemorativa da I Semana de Geografia. Rio de Janeiro: IBGE/Conselho Nacional de Geografia, 1963. 
objetos colecionados do Museu Nacional, no Rio de Janeiro. 0 gaúcho e o vaqueiro, segundo as fontes literárias e iconográficas, diferenciam-se pela combinação étnica, pelo caráter e pela própria vestimenta, e principalmente pelas habilidades e técnicas utilizadas face ao imperativo do meio físico. Essas diferenciações são também apresentadas na ficha 9, tornando possível estabelecer relações de convergência de representações, suas similaridades e detectar matrizes ou imagens paradigmáticas.

Ficha 10: 0 círculo de cultura

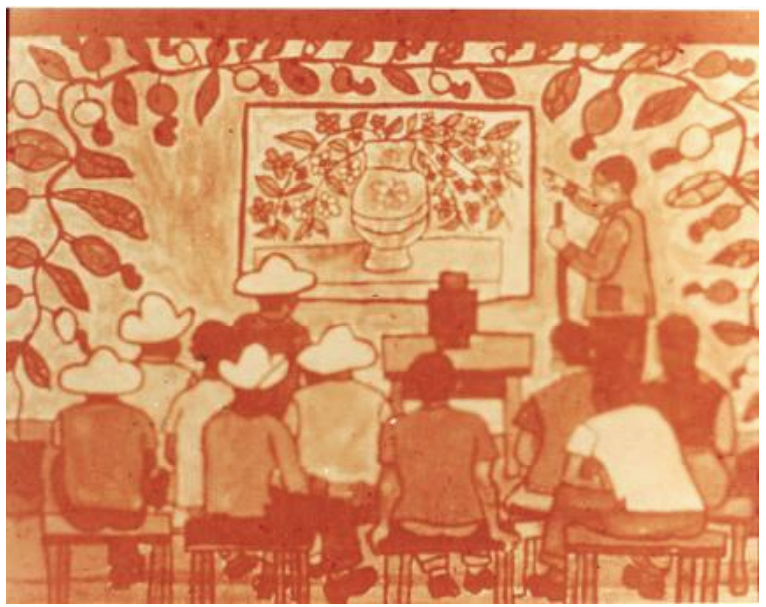

Nesta última situação, está presente a valorização da cultura letrada para a emancipação do povo que, através da comunicação, baseada no diálogo, é educada e simultaneamente educa. A identidade nacional, portanto, segue o pensamento otimista da educação. A democratização da cultura é um instrumento que permitirá a todos compreender o contexto histórico em que estão inseridos. Essa visão era recorrente durante a década de 1960, marcado pela efervescência política, social e cultural. Foi um momento no qual se questionava o modo de ser brasileiro, de viver e participar na história política e cultural do país. 0 objetivo principal era transformar a cultura brasileira e, através dela, pelas mãos do povo, transformar a ordem das relações de poder e a própria vida do país - projeto, como se sabe, interrompido bruscamente após o golpe militar de 31 de março de 1964.

\section{Moral da história}

No processo de divulgação e assimilação do conceito de cultura e cultura popular, no início dos anos de 1960, muito contribuiu a sistematização proposta 
por Paulo Freire nas fichas de cultura. É o que estou chamando de ovo de Colombo: assumíamos os mesmos conceitos e participávamos das mesmas aspirações, mas não sabíamos como aplicá-los e como realizá-las. Seguramente as fichas de cultura foram responsáveis pela vulgarização daqueles elementos fundamentais, e o mérito cabe a Paulo Freire.

Os conceitos de cultura e cultura popular foram sendo definidos durante 0 ano de 1962 e sua incorporação pelos movimentos de cultura e educação popular ocorreu durante o ano de 1963, sobretudo na "escalada" da implantação do Sistema Paulo Freire em muitos estados, mesmo antes da criação do Programa Nacional de Alfabetização. Entre o grupo formado pelos militantes da AP que trabalhava com alfabetização, e também pelo grupo do MEB, tornou-se lugar-comum discutir cultura e cultura popular a partir das fichas de cultura. Mesmo quando a hegemonia da AP na coordenação das ações de alfabetização foi quebrada pelo grupo marxista, na elaboração do PNA, na curta gestão de Júlio Sambaqui como Ministro da Educação, prevaleceu a utilização do Sistema de Alfabetização Paulo Freire, iniciado com a discussão das fichas de cultura. Segundo Vanilda Paiva (1973, p. 255-256; 2003, p. 283-284),

Neste momento, após a realização do $l^{0}$ Encontro de Alfabetização e Cultura Popular, buscava-se a formação de uma frente ampla em relação ao problema da educação dos adultos e isto determinou concessões entre os diversos grupos interessados no problema. Embora a nova mobilização fosse dirigida pelo coordenador do MPA [Movimento Popular de Alfabetização] da UNE, favorável à utilização de cartilhas, os entendimentos com os grupos católicos, bem como o prestígio pessoal do educador pernambucano, determinaram a aceitação do método Paulo Freire como instrumento do PNA.

Posteriormente, no entanto, as sucessivas adaptações do sistema de alfabetização foram progressivamente abandonando a discussão das fichas de cultura em sua fase inicial.

\section{Referências}

AÇÃO POPULAR. Educação popular. In: FÁVERO, Osmar. Cultura popular e educação popular; memória dos anos 60. Rio de Janeiro, Graal, 1983.

CHAUÍ, Marilena. Seminários: 0 nacional e o popular na cultura brasileira. Rio de Janeiro: Brasiliense, 1983.

ESTEVAM, Carlos. Cultura popular posta em questão. Rio de Janeiro: Civilização Brasileira, 1963; republicado por José Olympio, em 2002.

FÁVERO, Osmar. Cultura popular e educação popular: memória dos anos 60 . Rio de Janeiro, Graal, 1983. 
FREIRE, Paulo. Educação como prática da liberdade. Rio de Janeiro: Paz e Terra, 1967.

GULLAR, Ferreira. Cultura posta em questão. Rio de Janeiro: Ed. da UNE, 1963; republicado em 1965 pela Civilização Brasileira e reproduzido em Arte em Revista n. 3, março 1980. Na nova edição publicada pela José Olympio, em 2002: Cultura posta em questão; Vanguarda e subdesenvolvimento: ensaios sobre arte, o texto é precedido de um prefácio esclarecedor.

MEB - Movimento de Educação de Base. Fundamentação do programa para 1965 - $1^{a}$ parte: estudos sociais; 1.1 - cultura. Rio de Janeiro, 1965. 9 p., mimeo.

PAIVA, Vanilda Pereira. Educação popular e educação de adultos; contribuição à história da educação brasileira. São Paulo Loyola, 1973: ou História da educação popular no Brasil; educação popular e educação de adultos. São Paulo: Loyola, 2003.

SOUZA, Elisa Motta Moreira de. Tipos nacionais do Brasil: interpretações literárias e olhares iconográficos. Monografia de conclusão no Curso de Pedagogia da Universidade Federal Fluminense, em 2009.

SOARES, Leôncio e FÁVERO, Osmar (Orgs.). I Encontro Nacional de Alfabetização e Cultura Popular. Brasília: UNESCO/MEC, 2009. Disponível no portal mec.gov.br/ Coleção Educação para Todos v.33 e em <www.dhnet.org.br/dados/.../1>

TERRA, Antonia. Antes da hora. In: FERNANDES, Calazans \& TERRA, Antonia. 40 horas de esperança. 0 método Paulo Freire: política e pedagogia na experiência de Angicos. São Paulo: Ática, 1994.

Recebido em março de 2012

Aprovado em julho de 2012

Osmar Fávero possui graduação em Matemática pela Universidade Federal do Rio de Janeiro, mestrado em Educação pela Pontifícia Universidade Católica do Rio de Janeiro e doutorado em Filosofia da Educação pela Pontifícia Universidade Católica de São Paulo. Atualmente é professor aposentado da Universidade Federal Fluminense, atuando como colaborador permanente no Programa de Pós-Graduação em Educação da mesma Universidade. Tem experiência na área de Educação, com ênfase em política educacional, atuando principalmente nos seguintes temas: pós-graduação em educação, educação de jovens e adultos e educação popular. Email: ofaverodgmail.com. 